\title{
Metabolic response in roots of Prunus rootstocks submitted to iron chlorosis
}

Sergio Jiménez ${ }^{\mathrm{a}}$, Nathalie Ollat ${ }^{\mathrm{b}}$, Catherine Deborde ${ }^{\mathrm{c}, \mathrm{d}}$, Mickaël Maucourt ${ }^{\mathrm{c}, \mathrm{d}}$, Rubén RellánÁlvarez ${ }^{\mathrm{e}}$, María Ángeles Moreno ${ }^{\mathrm{a}}$, Yolanda Gogorcena*

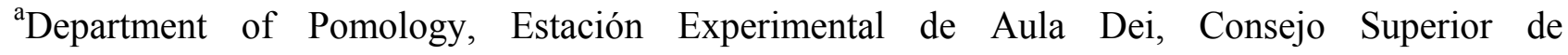
Investigaciones Científicas (CSIC), Apdo. 13034, E-50080 Zaragoza, Spain

${ }^{\mathrm{b}}$ INRA-UMR1287 Ecophysiology and Grape Functional Genomics, Institut des Sciences de la Vigne et du Vin (ISVV), BP 81, F-33883 Villenave d'Ornon, France


France

${ }^{\mathrm{d}}$ Metabolome-Fluxome Facility of Bordeaux Functional Genomics Centre, Centre INRA de Bordeaux, BP 81, F-33140 Villenave d'Ornon, France

${ }^{\mathrm{e} D e p a r t m e n t ~ o f ~ P l a n t ~ N u t r i t i o n, ~ E s t a c i o ́ n ~ E x p e r i m e n t a l ~ d e ~ A u l a ~ D e i, ~ C o n s e j o ~ S u p e r i o r ~ d e ~}$ Investigaciones Científicas (CSIC), Apdo. 13034, E-50080 Zaragoza, Spain 


\section{Summary}

Iron deficiency induces several mechanisms in response to iron shortage in plants. Metabolic changes occur to sustain the increased iron uptake capacity of Fe-deficient plants. We evaluated the metabolic changes of three Prunus rootstocks submitted to iron chlorosis and their different response for tolerance using measurements of metabolites and enzymatic activities. The more tolerant rootstocks Adesoto (Prunus insititia) and GF 677 (Prunus amygdalus $\times$ Prunus persica), and the more sensitive Barrier (P. persica $\times$ Prunus davidiana) were grown hydroponically in iron sufficient and deficient conditions during two weeks. Sugar, organic and amino acid concentrations of root tips were determined after two weeks of iron shortage by proton nuclear magnetic resonance spectroscopy of extracts. Complementary analyses of organic acids were performed by liquid chromatography coupled to mass spectrometry. The major soluble sugars found were glucose and sucrose. The major organic acids were malic and citric acids, and the major amino acid was asparagine. Iron deficiency increased root sucrose, total organic and amino acid concentrations and phosphoenolpyruvate carboxylase activity. After two weeks of iron deficiency, the malic, citric and succinic acid concentrations increased in the three rootstocks, although no significant differences were found among genotypes with different tolerance to iron chlorosis. The tolerant rootstock Adesoto showed higher total organic and amino acid concentrations. In contrast, the susceptible rootstock Barrier showed lower total amino acid concentration and phosphoenolpyruvate carboxylase activity values. These results suggest that the induction of this enzyme activity under iron deficiency, as previously shown in herbaceous plants, indicates the tolerance level of rootstocks to iron chlorosis. The analysis of other metabolic parameters, such as organic and amino acid concentrations, gives complementary information for selection of genotypes tolerant to iron chlorosis.

Keywords: iron, metabolites, phosphoenolpyruvate carboxylase, Prunus, rootstock

Abbreviations: ERETIC, Electronic Reference To access In vivo Concentrations; FC-R, ferric chelate reductase; MS, mass spectrometry; NMR, nuclear magnetic resonance; PCA, principal component analysis; PEPC, phosphoenolpyruvate carboxylase 


\section{Introduction}

Iron chlorosis is one of the major nutritional imbalances in fruit tree orchards grown in the Mediterranean area (Rombolà and Tagliavini, 2006) which occurs due to the limited iron bioavailability in aerobic and alkaline $\mathrm{pH}$ environments (Römheld and Nikolic, 2007). The genetic approach to prevent iron chlorosis is based on the use of tolerant rootstocks (Rombolà and Tagliavini, 2006). However, the most used tolerant rootstocks are usually susceptible to other stresses and can induce adverse effects in tree growth and yield (Tagliavini and Rombolà, 2001; Donnini et al., 2009). Therefore, selection of new tolerant rootstocks is necessary. In order to accelerate the breeding programs, they should benefit from new early evaluation methods to determine iron chlorosis tolerance (Jiménez et al., 2008; Donnini et al., 2009).

The almond $\times$ peach hybrid GF 677 is probably the most widely used rootstock for peach and nectarine in the Mediterranean area. It has high vigour and tolerance to drought and iron chlorosis (Cinelli and Loreti, 2004). Unlike other rootstocks sensitive to iron deficiency, the GF 677 rootstock is able to perform mechanisms of response against the lower iron soluble concentration in soil, characteristic of Strategy I plants, such as induction of the ferric chelate reductase activity (FCR) (Gogorcena et al., 2004; Jiménez et al., 2008) and proton extrusion (Molassiotis et al., 2006). The plum rootstock Adesoto is also considered as iron chlorosis tolerant (Moreno et al., 1995) and was also found to have an enhanced FC-R activity (Gogorcena et al., 2004; Jiménez et al., 2008). On the contrary, the peach-based rootstock Barrier was classified as less tolerant to iron chlorosis than GF 677 and Adesoto, and was not found to have an induction of FC-R activity (Gogorcena et al., 2004; Jiménez et al., 2008).

Iron deficiency induces root metabolic changes besides FC-R activity induction and rhizosphere acidification to sustain the increased iron uptake capacity of Fe-deficient plants. Carbohydrate, amino acid and especially organic acid concentrations often increase with iron deficiency in herbaceous plants (Abadía et al., 2002; Zocchi, 2006; M'Sehli et al., 2008). Carbohydrate concentration and rate of carbohydrate catabolism has been reported to increase under iron deficiency to sustain energetic requirements of the stressed plant (Zocchi, 2006; Jelali et al., 2010). Amino acid concentration has been reported to increase in order to sustain the major protein synthesis occurring under iron deficiency (Zocchi, 2006). Organic acids that make the sparingly soluble soil iron available to plants when they are excreted, could facilitate iron translocation and may be associated to proton extrusion and $\mathrm{Fe}^{3+}$ reduction activity (Abadía et al., 2002). Fixation of $\mathrm{CO}_{2}$ leading to organic acid biosynthesis is catalyzed by the enzyme phosphoenolpyruvate carboxylase (PEPC; EC4.1.1.31). PEPC activity stimulation was observed in iron deficient roots of several species (Rombolà et al., 2002; Ollat et al., 2003; Jiménez et al., 2007; Andaluz et al., 2009; 
López-Millán et al., 2009). Indeed, organic acid accumulation in roots of grapevine has been shown to be greater in Fe-efficient than in Fe-inefficient genotypes (Brancadoro et al., 1995; Ollat et al., 2003; Jiménez et al., 2007). Thus, changes in root concentration of these metabolites could indicate their tolerance level to iron deficiency.

Plant metabolites of tissue extracts are commonly identified and quantified by mass spectrometry (MS) or nuclear magnetic resonance spectroscopy (NMR) (Krishnan et al., 2005). One of the limitations of NMR is its low sensitivity. MS is several orders of magnitude more sensitive than NMR and allows the detection of low-abundance metabolites (Shulaev et al., 2008; Biais et al., 2009). However, the main disadvantage of MS is that it requires relatively longer analysis times, caused by the use of separation technologies such as gas chromatography (GC) and high performance liquid chromatography (HPLC) (Krishnan et al., 2005). Quantitative analysis is simpler in NMR than in MS where the generation of more complex spectrum, frequent calibration and variable retention times can complicate this task (Krishnan et al., 2005; Shulaev et al., 2008). Proton NMR ( ${ }^{1} \mathrm{H}$ NMR) provides a powerful technique for the identification and quantitative analysis of plant metabolites in complex mixtures (Moing et al., 2004; Pereira et al., 2006; Biais et al., 2009). The combined analysis of carbohydrate, amino and organic acids has been recently done in studies of plants under environmental stress, such as salinity in barley (Widodo et al., 2009) and iron-nitrogen nutrition in grapevine (Jiménez et al., 2007). The organic acid composition has been typically analyzed in iron deficiency response studies (Abadía et al., 2002; Ollat et al., 2003; LópezMillán et al., 2009). However, the use of ${ }^{1} \mathrm{H}$ NMR provides simultaneous information about changes in root sugar and also amino acid composition, a metabolic response poorly described previously in plants under iron deficiency.

The aim of the present work was to establish differences due to tolerance level, by studying the root metabolite composition of three Prunus rootstocks with different genetic background and level of tolerance to iron chlorosis, as well as searching for early biochemical markers of tolerance to iron deficiency.

\section{Material and methods}

\section{Plant material and culture}

Micropropagated plants of the tolerant rootstocks Adesoto [Prunus insititia (L.)] and GF 677 [Prunus amygdalus Batsch $\times$ Prunus persica (L.) Batsch] and the sensitive rootstock Barrier $[P$. persica (L.) Batsch $\times$ Prunus davidiana (Carr.) Franch.] (Gogorcena et al., 2004; Jiménez et al., 2008) were obtained from Agromillora Iberia S.A. (Subirats, Barcelona, Spain). Six plants per 
genotype were grown for two weeks in $300 \mathrm{~cm}^{3}$ pots containing a peat substrate. Then, they were transplanted to $10 \mathrm{~L}$ plastic containers (34 plants per container) filled with half-strength Hoagland nutrient solution (Jiménez et al., 2008). Plants were grown in a continuously aerated nutrient solution in a growth chamber under controlled environmental conditions, with a $16 \mathrm{~h}$ photoperiod (220-250 $\mu \mathrm{mol}$ photons $\left.\mathrm{m}^{-2} \mathrm{~s}^{-1}\right)$ at $23^{\circ} \mathrm{C}$ and $8 \mathrm{~h}$ of darkness at $20^{\circ} \mathrm{C}$, and $70-75 \%$ relative humidity. The $\mathrm{pH}$ of the nutrient solution was adjusted to 6 every two days, using $1 \mathrm{~N} \mathrm{HCl}$, and solution was changed every week.

Plants were grown in nutrient solution until roots were about $10-15 \mathrm{~cm}$ long and most of them were new. Then half of the plants were transferred to iron-free solutions [-Fe]. The rest of the plants were maintained in the solution containing $90 \mu \mathrm{M}$ Fe(III)-EDTA [+Fe] as control plants (Jiménez et al., 2008).

Root tip samples (about $15 \mathrm{~mm}$ long) of three [+Fe] and [-Fe] plants were taken after 14 days, rinsed in distilled water, weighed and deep-frozen in liquid nitrogen for metabolic profiling analysis. Additional samples were kept to measure PEPC activity. Three biological replicates were sampled for each analysis. Root and shoot fresh weights of plants were measured. The chlorophyll content of leaves was determined using a SPAD 502 chlorophyll meter (Minolta Co., Osaka, Japan).

\section{Metabolite sample extractions}

Samples (about 0.1 g FW root) for metabolite analyses were freeze crushed and polar compounds were extracted into aqueous ethanol at $80^{\circ} \mathrm{C}$, in three steps, each lasting 20 min (step 1:

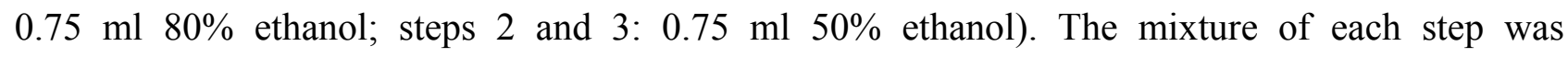
centrifuged for $10 \mathrm{~min}$ at $4800 \mathrm{~g}$ and slurries were pooled (Jiménez et al., 2007). Ethanol was evaporated under vacuum in a speed vac system (Thermo Fisher Scientific Inc., Waltham, MA, USA) and samples were split into two aliquots: one for ${ }^{1} \mathrm{H}$ NMR analysis of polar metabolites and the other for liquid chromatography-electrospray ionization/MS (LC-ESI-MS) analysis of organic acids.

\section{${ }^{1}$ H NMR spectroscopy to determine root metabolic profiles}

Dry extracts were solubilised in $1 \mathrm{~mL} 200 \mathrm{mM}$ oxalate buffer to maintain the $\mathrm{pH}$ of the extracts at 4.0. Samples were purified on $200 \mathrm{mg}$ of Chelex $100 \mathrm{resin}$ (Biorad, Hercules, CA, USA) in oxalate buffer at $\mathrm{pH} 4.0$, to improve spectrum resolution and eliminate paramagnetic ions. The resin was rinsed three times with $1 \mathrm{~mL}$ Milli-Q water. The $\mathrm{pH}$ of each sample was checked with a micro $\mathrm{pH}$ electrode after this step. The extracts were lyophilised, solubilised in $500 \mu \mathrm{L}_{2} \mathrm{O}$ and lyophilised again to eliminate residual water. The dried extracts were stored in a dry atmosphere until ${ }^{1} \mathrm{H}$ NMR analysis. Dried purified root extracts were solubilised in $500 \mu \mathrm{L} \mathrm{D}_{2} \mathrm{O}$, to which the 
sodium salt of (trimethylsilyl)propionic-2,3,3,3-d4 acid (TSP) in $\mathrm{D}_{2} \mathrm{O}$ was added to a final concentration of $0.01 \%$, for chemical shift calibration. The mixture was transferred to a NMR tube and ${ }^{1} \mathrm{H}$ NMR spectra were recorded as previously described (Moing et al., 2004) at $500.162 \mathrm{MHz}$ and $300 \mathrm{~K}$ on a Bruker Avance spectrometer (Wissenbourg, France), using a 5-mm inverse probe. We acquired 64 scans of $32 \mathrm{~K}$ data points with a spectral width of $6000 \mathrm{~Hz}$, a $90^{\circ}$ pulse angle and an acquisition time of $2.73 \mathrm{~s}$. The recycle delay was $15 \mathrm{~s}$. Data processing and assignments of metabolites were performed as described in Deborde et al. (2009). The metabolites assignment was obtained using comparison with chemical shift values reported in literature (Fan, 1996; Moing et al., 2004), Plant Metabolomic knowledge base MeRy-B (http://www.cbib.ubordeaux2.fr/MERYB/home/home.php) and spiking of root extracts with test compounds. The Electronic Reference To access In vivo Concentrations (ERETIC) method was used to determine absolute concentrations of metabolites as described in Jiménez et al. (2007). One unknown compound, named using the mid value of the chemical shift and the multiplicity of the corresponding resonance group (unknownD7.95 for a doublet at $7.95 \mathrm{ppm}$ ), was quantified in arbitrary units.

\section{LC-ESI-MS to determine root organic acid profiles}

Dried root samples were solubilised in Milli-Q water and filtered through $0.22 \mu \mathrm{m}$ polyvinylidene fluoride filters. The eluent was taken to a final volume of $2 \mathrm{~mL}$ with $0.1 \%(\mathrm{v} / \mathrm{v})$ formic acid and immediately analyzed. Analyses were carried out with a micrOTOF II ESI-TOFMS apparatus (Bruker Daltonics GmbH, Bremen, Germany) coupled to a Waters Alliance 2795 HPLC system (Waters, Milford, MA, USA). To optimize the MS signal, direct injection of $10 \mu \mathrm{M}$ solution of standards prepared in $0.1 \%(\mathrm{v} / \mathrm{v})$ formic acid were performed using a syringe pump (Cole-Parmer Instrument, Vernon Hills, IL, USA) operated at $180 \mu \mathrm{L} \mathrm{min}{ }^{-1}$. All analyses were done in negative mode. Drying and nebulizer gas $\left(\mathrm{N}_{2}\right)$ were kept at $1.6 \mathrm{psi}$ and $8.0 \mathrm{~L} \mathrm{~min}^{-1}$. The mass axis was calibrated using Li-formate adducts. Spectra were acquired in the mass/charge ratio $(\mathrm{m} / \mathrm{z})$ range of 80-300. LC-ESI-MS analyses were carried out by injection of $20 \mu \mathrm{L}$ aliquots of standard solutions and sample extracts in a Supelcogel H $250 \times 4.6 \mathrm{~mm}$ anion exchange column packed with a matrix of sulfonated polystyrene/divinylbenzene. Autosampler and column temperatures were $6^{\circ} \mathrm{C}$ and $30^{\circ} \mathrm{C}$, respectively. Samples were eluted at a flow rate of $200 \mu \mathrm{L}$ min. The mobile phase was $0.1 \%$ (v/v) formic acid and an isocratic gradient for 20 min was used to separate the compounds.

Validation was carried out by obtaining calibration curves corrected with internal standards (100 $\mu \mathrm{M}$ isotopically labeled malic acid was used for the quantification of oxalic, cis-aconitic, citric, malic and quinic acids; $100 \mu \mathrm{M}$ isotopically labeled succinic acid was used for the quantification of succinic acid), limits of detection (LODs, signal/noise ratio of 3), limits of quantification (LOQs, 
signal/noise ratio of 10 ), and intra- and interday repeatability, using standard techniques. The system was controlled with the software packages microTOF control 1.2 and HyStar 3.0 (Bruker Daltonics). Data were processed with Data Analysis 3.4 software (Bruker Daltonics).

\section{PEPC activity determination}

Extracts for measuring PEPC activity were made by grinding the frozen root material (about 0.1 g FW root) in liquid nitrogen in a mortar with $1 \mathrm{~mL}$ of extraction buffer, containing $100 \mathrm{mM}$ HEPES (pH 8.0), $30 \mathrm{mM}$ sorbitol, 1\% (w/v) PVP and 1\% (w/v) BSA (all chemicals from Sigma, St

Louis, MO, USA). The slurry was centrifuged for $15 \mathrm{~min}$ at $10,000 \mathrm{~g}$ and $4^{\circ} \mathrm{C}$, and the supernatant was used to determine enzyme activity.

PEPC activity was determined by coupling to malate dehydrogenase-catalysed NADH oxidation (Vance et al., 1983; Andaluz et al., 2002) with $0.75 \mu \mathrm{L}$ of extract in $1 \mathrm{~mL}$ of $2 \mathrm{mM}$ PEP, $0.16 \mathrm{mM} \mathrm{NADH}, 5 \mathrm{mM} \mathrm{MgCl} 2 \cdot 4 \mathrm{H}_{2} \mathrm{O}, 1 \mathrm{mM} \mathrm{NaHCO}$, and $50 \mathrm{mM}$ HEPES, pH 8.0. The NADH consumption was determined by monitoring at $25^{\circ} \mathrm{C}$ the decrease in absorbance at $340 \mathrm{~nm}$ with a spectrophotometer (UV-2101PC, Shimadzu, Kyoto, Japan).

\section{Statistical analysis}

Data were evaluated by two-way variance (ANOVA) analysis with the programme SPSS 17.0.0 (SPSS, Inc., Chicago, USA). When treatment interaction terms were significant $(P \leq 0.05)$, means were separated using Duncan's multiple range test at $P<0.05$. Principal component analysis (PCA) of 22 metabolites quantified by ${ }^{1} \mathrm{H}-\mathrm{NMR}$ and MS in 18 samples was carried out using SPSS 17.0.0. The component matrix (correlated matrix) was evaluated and orthogonal factors were rotated using variance maximizing (Varimax). Regression analysis was carried out by Pearson's correlation.

\section{Results}

\section{Morphologic parameters and SPAD}

After two weeks of iron deprivation, root growth was unaffected by iron deficiency and no differences among genotypes were found (Fig. 1A). Shoot growth was significantly higher in GF 677 [-Fe] plants (Fig. 1B). The elimination of iron from the growth medium significantly reduced the leaf chlorophyll content in all genotypes (Fig. 1C).

\section{Root metabolite concentration determined by ${ }^{1} \mathrm{H}-\mathrm{NMR}$}


The metabolic profiles of root tip extracts from the three genotypes were analyzed after 14 days of iron depletion. Nineteen compounds were identified in the NMR spectra (Fig. 2). Chlorogenic acid was only detected in Adesoto samples (Fig. 2, around 6.4, 7.0 and 7.2 ppm). Among the identified compounds, 15 were quantified: two sugars, one cyanogenic compound (prunasin), seven amino acids (glutamic acid and glutamine were quantified as their sum), four organic acids and one quaternary amine (choline) (Table 1). One other compound was quantified in arbitrary units, although it was not identified (Table 1).

Iron deficiency had no effect on glucose concentration after 14 days of depletion (Table 1). However, sucrose concentration was higher in deficient plants than sufficient ones, and prunasin concentration was lower. A significant genotype effect was found for prunasin. The peach-based rootstock Barrier showed the highest accumulation of this cyanogenic compound under control conditions.

In general, iron deficiency increased amino acid concentrations (Table 1). After two weeks, iron deficiency had significant effect in several amino acids: glutamic acid + glutamine, threonine, valine and especially alanine which concentration increased 2.3, 3.3 and 2.5 fold on Adesoto (see comparison frame in Fig 2 at 1.4-1.5 ppm), Barrier and GF 677, respectively. Genotype had also significant effect in all amino acid concentrations except alanine and GABA (Table 1). The total sum of amino acids was significantly higher in deficient plants than in control ones, and it was always lower on Barrier rootstock (Fig. 3A).

Iron deficiency significantly increased the concentration in organic acids detected other than lactic acid (Table 1). Malic acid concentration increased 1.9 and 1.3 fold on Adesoto (see comparison frame in Fig 2 at 4.4 ppm) and GF 677, respectively, whereas citric acid concentration increased 2.6 and 1.5 fold in both genotypes (see comparison frame in Fig 2 at 2.7-2.9 ppm for Adesoto). In Barrier, malic acid concentration increased 2.7 fold and citric acid concentration increased 16.3 fold. However on day 14, sufficient plants of Barrier rootstock showed very low root concentrations of citric acid $\left(0.15 \pm 0.01 \mathrm{mg} \mathrm{g}^{-1} \mathrm{FW}\right)$ in comparison with control determinations of previous days $\left(1.76 \pm 0.38 \mathrm{mg} \mathrm{g}^{-1} \mathrm{FW}\right.$ after 7 days of the beginning of the experiment). Succinic acid concentration increased 2.7, 1.4 and 1.4 fold on Adesoto (see comparison frame in Fig 2 at 2.6 ppm), Barrier and GF 677, respectively. For all studied rootstocks, the total organic acid concentration was significantly higher in deficient than in control plants (Fig. 3B).

Choline and one unidentified compound were also quantified (Table 1; Fig 2 around 3.2 and 8.0 ppm). The concentration of choline was significantly affected by genotype whereas no treatment effect was observed for this compound. The unknownD7.95 compound concentration was not significantly affected by treatment or genotype. 


\section{Root organic acid profiles determined by MS}

Root organic acid concentrations were also determined by LC-ESI-MS analysis (Table 2). Concentration values of malic and citric acids were not significantly different to the values obtained with ${ }^{1} \mathrm{H}$ NMR (data not shown). On the other hand, LC-ESI-MS concentration values of succinic acid were significantly underestimated $(P<0.01)$. However, values obtained with both techniques were significantly correlated (malic acid, $\mathrm{r}=0.92, P \leq 0.001$; citric acid, $\mathrm{r}=0.87, P \leq 0.001$; succinic acid, $r=0.95, P \leq 0.001$ ), the total sums of these three organic acids were not different between techniques (data not shown), and a similar effect of iron treatment was observed in the data obtained with MS in comparison with ${ }^{1} \mathrm{H}$ NMR. Three other organic acids (oxalic, cis-aconitic and quinic acids) were also identified and quantified (Table 2). Iron deficiency and genotype had significant effects in the concentration of cis-aconitic and quinic acids. The concentration of cisaconitic acid increased significantly with iron deficiency except in GF 677.

\section{Principal component analysis for metabolites}

A PCA was performed on ${ }^{1} \mathrm{H}$ NMR and MS data of the three genotypes after two weeks of iron deficiency or under control condition in order to get an overview of the metabolite changes (Fig. 4). A five component model accounted for more than $80 \%$ of total variance, with the first three components explaining $67.7 \%$ of total variance. $\mathrm{PC} 1$ and $\mathrm{PC} 2$ accounted for $37.3 \%$ and $18.4 \%$ of total variance, respectively.

Subsamples were clustered with the exception of GF 677 [-Fe] and Barrier [+Fe], which displayed greater variability (Fig. 4A). PC1 discriminated [-Fe] and $[+\mathrm{Fe}]$ samples with the exception of two sample replications of GF 677 [-Fe] and one sample of GF 677 [+Fe] (Fig. 4A). An examination of PC1 loadings (Fig. 4B) suggested that this separation was mainly due to alanine, and the organic acids, malic, citric, succinic, oxalic and cis-aconitic acids, on the positive side. PC2 discriminated Adesoto from the other two rootstocks. An examination of PC2 loadings (Fig. 4B) suggested that this separation was mainly due to the main amino acids (asparagine, glutamic acid + glutamine, isoleucine, threonine and valine) and choline on the positive side and glucose on the negative side. These observations found in the multivariate analysis confirmed the two-way ANOVA analysis (Tables 1-2). Organic acids determined by both ${ }^{1} \mathrm{H}-\mathrm{NMR}$ and MS techniques (malic, citric and succinic acids) were also clustered.

\section{Phosphoenolpyruvate carboxylase activity}

PEPC activity was measured in the three genotypes after 14 days of iron depletion and under control condition (Fig. 5). Iron deficiency resulted in a significant stimulation of this activity in Adesoto (1.9-fold) and GF 677 (4.9-fold). However, almost no induction on PEPC activity was 
found in the case of Barrier. A highly significant interaction between iron treatment and genotype was found. PEPC activity was correlated with sucrose $(\mathrm{r}=0.64, P \leq 0.01)$, alanine $(\mathrm{r}=0.61, P \leq$ $0.01)$, asparagine $(\mathrm{r}=0.63, P \leq 0.001)$ and the total amino acid concentration $(\mathrm{r}=0.64, P \leq 0.01)$.

\section{Discussion}

The analysis of metabolites contributes significantly to the study of stress biology in plants by identifying compounds that are part of their acclimation or tolerance response (Shulaev et al., 2008). In the present study, we used ${ }^{1} \mathrm{H}$ NMR to analyze the metabolite changes in Prunus roots induced by iron deficiency. The NMR technique allowed the simultaneous study of a number of metabolites including primary and secondary polar and semipolar metabolites in a complex mixture, such as root extracts, with minimal sample preparation (Moing et al., 2004). Sugars, amino acids, organic acids and other compounds were quantified with rapid data processing using the ${ }^{1} \mathrm{H}$ NMR technology. Organic acid quantification was complemented using MS analysis, a more timeconsuming but sensitive technique than ${ }^{1} \mathrm{H}$ NMR (Shulaev et al., 2008). Lower abundant organic acids such as oxalic, cis-aconitic and quinic acids were only detected and quantified with MS. The combination ${ }^{1} \mathrm{H}$ NMR and MS increased the coverage of metabolites quantified with small discrepancies due to the different calibration methods used in these two techniques. Moreover, both analytical techniques showed a similar trend for the organic acids determined with both in roots of plants submitted to iron nutrition treatments.

\section{Iron deficiency induces the root accumulation of sugars, organic and amino acids}

Soluble sugar accumulation has been reported in roots of fruit trees subjected to abiotic stress: sucrose under low temperatures (Yoshioka et al., 1988) and sorbitol under drought stress in Malus (Meng et al., 2008), and sorbitol under iron stress in quince (Marino et al., 2000). High concentrations of fructose and sorbitol and small amounts of raffinose were also found in roots of peach and peach-almond hybrid iron deficient rootstocks using HPLC (Graham, 2002; Jiménez, 2006). Iron deficiency induced sucrose accumulation in roots of the three Prunus rootstocks studied. Reduction in plant growth of deficient plants would produce apparently higher metabolite concentrations. However, in this study there were not significant changes in root growth between treatments, as previously reported (Jiménez et al., 2009). Therefore, sucrose accumulation (and any other metabolite accumulation) seems to be independent of a possible concentration effect in deficient plants. During prolonged iron deficiency, the increase in root sugar concentration for glucose, fructose and sucrose concentration of GF 677 was already reported (Jiménez, 2006). Since 
the root glycolytic (Zocchi, 2006; Jelali et al., 2010) and fermentation (Thimm et al., 2001) routes are enhanced under iron deficiency, the sugar accumulation may come from starch degradation and/or re-orientation of photo-assimilate partitioning (Loescher et al., 1990), probably via sorbitol or sucrose.

The accumulation of amino acids and derivates has been related to plant responses and adaptation to metal stresses. The metal binding capacity and antioxidant defence are major functions of these compounds in plants submitted to metal excess (Sharma and Dietz, 2006). We found that iron deficiency increased amino acid concentrations (alanine, valine, threonine and glutamic acid + glutamine) in roots of Prunus rootstocks. However, alanine and glutamic acid + glutamine concentration were not affected by iron deficiency in roots of grapevine rootstocks (Jiménez et al., 2007). Pontiggia et al. (2003) have reported the enhanced RNA and protein synthesis with better developed machinery and accumulation of free amino acids in cucumber roots submitted to iron deficiency. An increased root exudation of total amino acids with iron deficiency has been also reported in soybean (Zocchi et al., 2007). We found that alanine was especially accumulated in deficient roots. This amino acid was showed as metal ion ligand found in barley exudates although it did not exhibit a clear response to iron deficiency (Fan et al., 2001).

The accumulation of root organic acids, particularly malic and citric acids, has been also reported in some woody plant species submitted to iron deficiency, such as grapevine rootstocks (Brancadoro et al., 1995; Ollat et al., 2003; Jiménez et al., 2007), kiwifruit (Rombolà et al., 2002) and in a certain extent in quince rootstocks (Marino et al., 2000). The main organic acids found in Prunus rootstocks subjected to iron deficiency in the present experiment were malic and citric acids, although their increases were much lower than those found in herbaceous plants. In sugar beet, the increase of malic and citric acids reached 16 and 26 fold, respectively, after 10 days of iron deficiency (López-Millán et al., 2000). Conversely, the concentration of malic and citric acids increased only 1.1-2.6-fold in Prunus roots, being slightly lower than those found in grapevine (Jiménez et al., 2007). On the other hand, succinic acid was also accumulated after two weeks under iron deficiency, as previously reported in grapevine (Jiménez et al., 2007). Concentration of succinic and quinic acids were also increased with iron deficiency in other tissues in peach, such as fruits (Álvarez-Fernández et al., 2003).

\section{Iron deficiency stimulates the root PEPC activity in the tolerant genotypes}

PEPC enzyme plays a central role in the response of plants to iron deficiency (Zocchi, 2006). The more tolerant rootstocks to iron deficiency, Adesoto and GF 677, showed a significant stimulation of PEPC activity under iron deficiency, as previously reported in other woody species: grapevine (Ollat et al., 2003; Jiménez et al., 2007), kiwi (Rombolà et al., 2002) and pear/quince 
(Donnini et al., 2009). On the other hand, the more sensitive rootstock Barrier showed the lowest PEPC activity values, both under sufficient and deficient conditions.

\section{Integrated metabolic response to iron deficiency and differences among Prunus genotypes}

The observed changes, mainly increase in sugar, organic acid and amino acid concentrations of Prunus roots, may contribute to iron deficiency stress response. Sugar concentration increase may face the high energy demand required for iron deficiency response and the supply of carbon to the organic and amino acids. Increase in PEPC activity would sustain the carbon replenishment in the tricarboxylic acid cycle, the enhanced synthesis of malic, citric and amino acids, via 2-oxoglutarate (glutamic acid, glutamine) and oxalacetate (asparagine, isoleucine, threonine). Indeed, activation of PEPC leading to an increase in the rate of glycolysis (Zocchi, 2006) and production of 2oxoglutarate would produce reducing equivalents for the FC-R (Jiménez et al., 2007). On the other hand, the role suggested for the organic acids comprise its use as chelates of iron in soil or xylem, a source to obtain reductive power and a source of anaplerotic carbon in leaves (Abadía et al., 2002), although the excretion of organic acids in Prunus rootstocks remain unknown. Indeed, since iron deficiency can induce the accumulation of other metals such as Mn, $\mathrm{Zn}$ and $\mathrm{Cu}$ (Jiménez et al., 2009), organic and amino acids could be involved in metal binding (Sharma and Dietz, 2006) to avoid oxidative damage due to other catalytic ions.

The three Prunus rootstocks showed different metabolic response to iron deficiency. However, despite differences in organic acid concentrations were found between Fe-efficient and Feinefficient genotypes of grapevine (Brancadoro et al., 1995; Jiménez et al., 2007) and kiwi (Rombolà et al., 2002), no significant differences were found among the studied Prunus genotypes in response to iron deficiency. The moderate symptoms of iron chlorosis detected in the tolerant rootstock GF 677 (higher SPAD values in leaf than the other genotypes) may explain the absence of citric acid accumulation after two weeks of iron deficiency. The high citric acid concentration found in the sensitive rootstock Barrier submitted to iron deficiency could be caused by a low synthesis of amino acids, especially asparagine, and, therefore, a lower consumption of organic acids from the tricarboxylic acid cycle. The unexpected high citric acid concentration of Barrier could explain the moderate chlorophyll concentration found in grafted plants grown on calcareous soil (Jiménez, 2006), even though it has low FC-R activation (Gogorcena et al., 2004) iron transport to leaves can be facilitated. In contrast, differences among rootstocks were found for PEPC activity. The more tolerant rootstocks, Adesoto and GF 677, showed higher induction and values of PEPC activity after iron deficiency. The lack of iron also induced higher amino acid concentration in the two more tolerant rootstocks. Regardless of treatment, the amino acid and choline concentration was higher in 
the $P$. insititia rootstock Adesoto than the P. persica based rootstocks Barrier and GF 677. This could be caused by species specific differences.

In summary, the plum rootstock Adesoto and the peach based rootstocks Barrier and GF 677 showed several responses characteristics of Strategy I efficient plants under iron deficiency, such as enhanced root PEPC activity and malic, citric and succinic acid accumulation. Indeed, iron deficiency induced soluble sugar and amino acid accumulation related with the response of woody plants to iron shortage. Unlike other woody plants, citric acid concentration was not an indicator of tolerance to iron chlorosis in Prunus plants, however, PEPC activity and accumulation of amino acids could be partly related with tolerance in Prunus rootstocks to iron chlorosis.

\section{Acknowledgments}

This work was partly funded by the Spanish-French bilateral cooperation programs (Picasso Program-HF2003-273; Aquitaine-Aragón Aq23 and Aq25) and the Spanish MICINN (Ministerio de Ciencia e Innovación, grants AGL-2005-05533, AGL-2008-00283 and AGL2009-09018). Sergio Jiménez was supported by an I3P fellowship from CSIC/FSE (Consejo Superior de Investigaciones Científicas/Fondo Social Europeo) and a travel fellowship from DGA/CAI (CA 5/03). We thank Dr. Annick Moing for valuable discussions and critical reading of the manuscript, Rosa Giménez for excellent technical assistance and Agromillora Iberia S.A. for providing plant material.

\section{References}

Abadía J, López-Millán AF, Rombolà A, Abadía A. Organic acids and Fe deficiency: a review. Plant Soil 2002;241:75-86.

Álvarez-Fernández A, Paniagua P, Abadía J, Abadía A. Effects of Fe deficiency chlorosis on yield and fruit quality in peach (Prunus persica L. Batsch). J Agric Food Chem 2003;51:57385744.

Andaluz S, López-Millán AF, Peleato ML, Abadía J, Abadía A. Increases in phosphoenolpyruvate carboxylase activity in iron-deficient sugar beet roots: Analysis of spatial localization and post-translational modification. Plant Soil 2002;241:43-48.

Andaluz S, Rodríguez-Celma J, Abadía A, Abadía J, López-Millán A-F. Time course induction of several key enzymes in Medicago truncatula roots in response to Fe deficiency. Plant Physiol Biochem 2009;47:1082-1088. 
Biais B, Allwood JW, Deborde C, Xu Y, Maucourt M, Beauvoit B, Dunn WB, Jacob D, Goodacre R, Rolin D, Moing A. ${ }^{1} \mathrm{H}$ NMR, GC-EI-TOFMS, and data set correlation for fruit metabolomics: application to spatial metabolite analysis in melon. Anal Chem 2009;81:2884-2894.

Brancadoro L, Rabotti G, Scienza A, Zocchi G. Mechanisms of Fe-efficiency in roots of Vitis spp. in response to iron-deficiency stress. Plant Soil 1995;171:229-234.

Cinelli F, Loreti F. Evaluation of some plum rootstocks in relation to lime-induced chlorosis by hydroponic culture. Acta Hortic 2004;658:421-427.

Deborde C, Maucourt M, Baldet P, Bernillon S, Biais B, Talon G, Ferrand C, Jacob D, FerryDumazet H, de Daruvar A, Rolin D, Moing A. Proton NMR quantitative profiling for quality assessment of greenhouse-grown tomato fruit. Metabolomics 2009;5:183-198.

Donnini S, Castagna A, Ranieri A, Zocchi G. Differential responses in pear and quince genotypes induced by Fe deficiency and bicarbonate. J Plant Physiol 2009;166:1181-1193.

Fan TW, Lane AN, Shenker M, Bartley JP, Crowley D, Higashi RM. Comprehensive chemical profiling of graminaceous plant root exudates using high-resolution NMR and MS. Phytochemistry 2001;57:209-221.

Fan WMT. Metabolite profiling by one- and two-dimensional NMR analysis of complex mixtures. Prog Nucl Magn Reson Spectrosc 1996;28:161-219.

Gogorcena Y, Abadía J, Abadía A. A new technique for screening iron-efficient genotypes in peach rootstocks elicitation of root ferric chelate reductase by manipulation of external iron concentrations. J Plant Nutr 2004;27:1701-1715.

Graham CJ. Nonstructural carbohydrate and prunasin composition of peach seedlings fertilized with different nitrogen sources and aluminum. Sci Hortic 2002;94:21-32.

Jelali N, Wissal Ms, Dell'orto M, Abdelly C, Gharsalli M, Zocchi G. Changes of metabolic responses to direct and induced Fe deficiency of two Pisum sativum cultivars. Environ Exp Bot 2010;68:238-246.

Jiménez S. Selección de patrones frutales de hueso tolerantes a la clorosis férrica. Aspectos nutricionales y metabólicos. PhD dissertation: University of Zaragoza, 2006. p. 227.

Jiménez S, Gogorcena Y, Hévin C, Rombolà AD, Ollat N. Nitrogen nutrition influences some biochemical responses to iron deficiency in tolerant and sensitive genotypes of Vitis. Plant Soil 2007;290:343-355.

Jiménez S, Pinochet J, Abadía A, Moreno MA, Gogorcena Y. Tolerance response to iron chlorosis of Prunus selections as rootstocks. HortScience 2008;43:304-309. 
Jiménez S, Morales F, Abadía A, Abadía J, Moreno MA, Gogorcena Y. Elemental 2-D mapping and changes in leaf iron and chlorophyll in response to iron re-supply in iron-deficient GF 677 peach-almond hybrid. Plant Soil 2009;315:93-106.

Krishnan P, Kruger NJ, Ratcliffe RG. Metabolite fingerprinting and profiling in plants using NMR. J Exp Bot 2005;56:255-265.

Loescher WH, McCamant T, Keller JD. Carbohydrate reserves, translocation, and storage in woody plant roots. HortScience 1990;25:274-281.

López-Millán A-F, Morales F, Andaluz S, Gogorcena Y, Abadía A, De las Rivas J, Abadía J. Protective mechanisms in roots of iron deficient sugar beet: changes in carbon assimilation and oxygen use. Plant Physiol 2000;124:885-897.

López-Millán AF, Morales F, Gogorcena Y, Abadía A, Abadía J. Metabolic responses in iron deficient tomato plants. J Plant Physiol 2009;166:375-384.

M'Sehli W, Youssfi S, Donnini S, Dell'Orto M, De Nisi P, Zocchi G, Abdelly C, Gharsalli M. Root exudation and rhizosphere acidification by two lines of Medicago ciliaris in response to lime-induced iron deficiency. Plant Soil 2008;312:151-162.

Marino G, Beghelli S, Rombolà AD, Cabrini L. In vitro performance at high culture $\mathrm{pH}$ and in vivo responses to Fe-deficiency of leaf-derived quince BA 29 (Cydonia oblonga) somaclones regenerated at variable medium pH. J Hortic Sci Biotechnol 2000;75:433-440.

Meng YL, Xu XF, Khanizadeh S, Zhang MJ, Wang Q, Han ZH. Contribution of abscisic acid to sorbitol accumulation in drought-stressed Malus hupehensis. J Food Agric Environ 2008;6:319-326.

Moing A, Maucourt M, Renaud C, Gaudillère M, Brouquisse R, Lebouteiller B, Gousset-Dupont A, Vidal J, Granot D, Denoyes-Rothan B, Lerceteau-Köhler E, Rolin D. Quantitative metabolic profiling by 1-dimensional ${ }^{1} \mathrm{H}-\mathrm{NMR}$ analyses: application to plant genetics and functional genomics. Funct Plant Biol 2004;31:889-902.

Molassiotis A, Tanou G, Diamantidis G, Patakas A, Therios I. Effects of 4-month Fe deficiency exposure on $\mathrm{Fe}$ reduction mechanism, photosynthetic gas exchange, chlorophyll fluorescence and antioxidant defense in two peach rootstocks differing in Fe deficiency tolerance. J Plant Physiol 2006;163:176-185.

Moreno MA, Tabuenca MC, Cambra R. Adesoto 101, a plum rootstock for peaches and other stone fruit. HortScience 1995;30:1314-1315.

Ollat N, Laborde B, Neveux M, Diakou-Verdin P, Renaud C, Moing A. Organic acid metabolism in roots of various grapevine (Vitis) rootstocks submitted to iron deficiency and bicarbonate nutrition. J Plant Nutr 2003;26:2165-2176. 
Pereira GE, Gaudillere JP, van Leeuwen C, Hilbert G, Maucourt M, Deborde C, Moing A, Rolin D.

${ }^{1} \mathrm{H}$ NMR metabolite fingerprints of grape berry: comparison of vintage and soil effects in Bordeaux grapevine growing areas. Anal Chim Acta 2006;563:346-352.

Pontiggia A, De Nisi P, Zocchi G. Effect of iron deficiency on RNA and protein synthesis in cucumber roots. J Plant Nutr 2003;26:2177-2186.

Rombolà $\mathrm{AD}$, Tagliavini M. Iron nutrition of fruit tree crops. In: Barton LL, Abadía J, editors. Iron Nutrition in Plants and Rizhospheric Micoorganisms. Dordrecht, Netherlands: Springer, 2006. p 61-83.

Rombolà AD, Brüggemann W, López-Millán A-F, Tagliavini M, Abadía J, Marangoni B, Moog PR. Biochemical responses to iron deficiency in kiwifruit (Actinidia deliciosa). Tree Physiol 2002;22:869-875.

Römheld V, Nikolic M. Iron. In: Barker AV, Pilbeam DJ, editors. Handbook of Plant Nutrition. Boca Raton, FL, USA: CRC Press, Taylor \& Francis Group, 2007. p 329-350.

Sharma SS, Dietz K-J. The significance of amino acids and amino acid-derived molecules in plant responses and adaptation to heavy metal stress. J Exp Bot 2006;57:711-726.

Shulaev V, Cortes D, Miller G, Mittler R. Metabolomics for plant stress response. Physiol Plant 2008;132:199-208.

Tagliavini M, Rombolà AD. Iron deficiency and chlorosis in orchard and vineyard ecosystems. Eur J Agron 2001;15:71-92.

Thimm O, Essigmann B, Kloska S, Altmann T, Buckhout TJ. Response of Arabidopsis to iron deficiency stress as revealed by microarray analysis. Plant Physiol 2001;127:1030-1043.

Vance CP, Stade S, Maxwell CA. Alfalfa root nodule carbon dioxide fixation. I. Association with nitrogen fixation and incorporation into amino acids. Plant Physiol 1983;72:469-473.

Widodo, Patterson JH, Newbigin E, Tester M, Bacic A, Roessner U. Metabolic responses to salt stress of barley (Hordeum vulgare L.) cultivars, Sahara and Clipper, which differ in salinity tolerance. J Exp Bot 2009;60:4089-4103.

Yoshioka H, Nagai K, Aoba K, Fukumoto M. Seasonal changes of carbohydrates metabolism in apple trees. Sci Hortic 1988;36:219-227.

Zocchi G. Metabolic changes in iron-stressed dicotyledonous plants. In: Barton LL, Abadía J, editors. Iron Nutrition in Plants and Rizhospheric Microorganisms. Dordrecht, Netherlands: Springer, 2006. p 359-370.

Zocchi G, De Nisi P, Dell'Orto M, Espen L, Gallina PM. Iron deficiency differently affects metabolic responses in soybean roots. J Exp Bot 2007;58:993-1000. 
Table 1. Concentration of the main compounds ( $\mathrm{mg} \mathrm{g}^{-1} \mathrm{FW}$ ) determined by ${ }^{1} \mathrm{H}$ NMR, in root tip extracts of Prunus rootstocks (Adesoto, Barrier and GF 677) after 14 days of growth in nutrient solution containing $90 \mu \mathrm{M} \mathrm{Fe}(\mathrm{III})$-EDTA [+Fe] or $0 \mu \mathrm{M}$ Fe(III)-EDTA [-Fe]. Data are means \pm SE of three replicates.

\begin{tabular}{|c|c|c|c|c|c|c|c|c|c|}
\hline \multirow{2}{*}{$\begin{array}{l}\text { Rootstock } \\
\text { Fe treatment }\end{array}$} & \multicolumn{2}{|c|}{ Adesoto } & \multicolumn{2}{|c|}{ Barrier } & \multicolumn{2}{|c|}{ GF 677} & \multicolumn{3}{|c|}{ Significance $^{\mathrm{a}}$} \\
\hline & {$[+\mathrm{Fe}]$} & {$[-\mathrm{Fe}]$} & {$[+\mathrm{Fe}]$} & {$[-\mathrm{Fe}]$} & {$[+\mathrm{Fe}]$} & {$[-\mathrm{Fe}]$} & $\mathrm{Fe}$ & G & $\mathrm{Fe} \times \mathrm{G}$ \\
\hline \multicolumn{10}{|l|}{ Sugars } \\
\hline Glucose & $1.96 \pm 0.33$ & $1.43 \pm 0.23$ & $2.79 \pm 0.56$ & $3.03 \pm 0.08$ & $2.53 \pm 0.65$ & $2.10 \pm 0.31$ & NS & $*$ & NS \\
\hline Sucrose & $0.26 \pm 0.04$ & $0.53 \pm 0.21$ & $0.06 \pm 0.04$ & $0.18 \pm 0.03$ & $0.00 \pm 0.00^{\mathrm{b}}$ & $0.68 \pm 0.24$ & $* *$ & NS & NS \\
\hline \multicolumn{10}{|l|}{ Cyanogenic compound } \\
\hline Prunasin & $0.50 \pm 0.14 \mathrm{a}$ & $0.15 \pm 0.04 \mathrm{a}$ & $1.45 \pm 0.17 \mathrm{~b}$ & $0.49 \pm 0.05 \mathrm{a}$ & $0.58 \pm 0.19 \mathrm{a}$ & $0.51 \pm 0.22 \mathrm{a}$ & $* *$ & $* *$ & $*$ \\
\hline \multicolumn{10}{|l|}{ Amino acids } \\
\hline Alanine & $0.093 \pm 0.027$ & $0.216 \pm 0.040$ & $0.046 \pm 0.020$ & $0.151 \pm 0.034$ & $0.070 \pm 0.012$ & $0.172 \pm 0.040$ & $* * *$ & NS & NS \\
\hline Asparagine & $2.19 \pm 1.08$ & $3.15 \pm 0.32$ & $0.23 \pm 0.02$ & $0.80 \pm 0.12$ & $1.58 \pm 0.63$ & $2.39 \pm 0.61$ & NS & $* *$ & NS \\
\hline GABA & $0.079 \pm 0.012$ & $0.104 \pm 0.055$ & $0.030 \pm 0.028$ & $0.083 \pm 0.019$ & $0.051 \pm 0.005$ & $0.052 \pm 0.009$ & NS & NS & NS \\
\hline Glutamic acid + Glutamine & $0.27 \pm 0.05$ & $0.48 \pm 0.05$ & $0.16 \pm 0.01$ & $0.19 \pm 0.02$ & $0.20 \pm 0.05$ & $0.22 \pm 0.01$ & $*$ & $* * *$ & NS \\
\hline Isoleucine & $0.023 \pm 0.005$ & $0.031 \pm 0.002$ & $0.005 \pm 0.004$ & $0.012 \pm 0.001$ & $0.016 \pm 0.004$ & $0.011 \pm 0.007$ & NS & $* *$ & NS \\
\hline Threonine & $0.027 \pm 0.006$ & $0.036 \pm 0.001$ & $0.012 \pm 0.004$ & $0.023 \pm 0.003$ & $0.016 \pm 0.005$ & $0.018 \pm 0.002$ & $*$ & $* *$ & NS \\
\hline Valine & $0.012 \pm 0.004$ & $0.021 \pm 0.001$ & $0.003 \pm 0.002$ & $0.008 \pm 0.002$ & $0.007 \pm 0.002$ & $0.008 \pm 0.001$ & $*$ & $* * *$ & NS \\
\hline \multicolumn{10}{|l|}{ Organic acids } \\
\hline Citric acid & $0.98 \pm 0.18 b$ & $2.55 \pm 0.44 \mathrm{~d}$ & $0.15 \pm 0.01 \mathrm{a}$ & $2.44 \pm 0.56 \mathrm{~cd}$ & $0.95 \pm 0.18 b$ & $1.41 \pm 0.42 \mathrm{bc}$ & $* * *$ & $* * *$ & $* * *$ \\
\hline Malic acid & $0.75 \pm 0.16$ & $1.42 \pm 0.02$ & $0.44 \pm 0.15$ & $1.18 \pm 0.27$ & $0.96 \pm 0.20$ & $1.23 \pm 0.30$ & $* *$ & NS & NS \\
\hline Succinic acid & $0.070 \pm 0.006$ & $0.186 \pm 0.021$ & $0.085 \pm 0.021$ & $0.117 \pm 0.012$ & $0.082 \pm 0.017$ & $0.116 \pm 0.021$ & $* * *$ & NS & NS \\
\hline Lactic acid & $0.031 \pm 0.002$ & $0.042 \pm 0.003$ & $0.060 \pm 0.025$ & $0.052 \pm 0.007$ & $0.021 \pm 0.004$ & $0.038 \pm 0.009$ & NS & NS & NS \\
\hline \multicolumn{10}{|l|}{ Amide } \\
\hline Choline & $1.32 \pm 0.15$ & $1.05 \pm 0.04$ & $0.77 \pm 0.09$ & $0.63 \pm 0.05$ & $0.57 \pm 0.13$ & $0.59 \pm 0.06$ & NS & $* * *$ & NS \\
\hline \multicolumn{10}{|l|}{ Unknown compound } \\
\hline UnknownD7.95 & $0.29 \pm 0.05$ & $0.34 \pm 0.04$ & $0.43 \pm 0.05$ & $0.45 \pm 0.06$ & $0.43 \pm 0.07$ & $0.23 \pm 0.04$ & NS & NS & NS \\
\hline
\end{tabular}



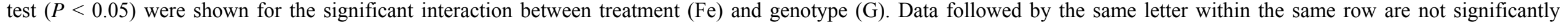
different. Glutamate + Glutamine expressed as glutamine equivalent.

${ }^{\mathrm{b}}$ Not detetected 
Table 2. Concentration of the main organic acids ( $\mathrm{mg} \mathrm{g}^{-1} \mathrm{FW}$, cis-aconitic acid needs to be multiplied by $10^{-3}$ ) determined by HPLC-ESI/MSTOF, in root tip extracts of Prunus rootstocks (Adesoto, Barrier and GF 677) after 14 days of growth in nutrient solution containing $90 \mu \mathrm{M} \mathrm{Fe(III)-EDTA} \mathrm{[+Fe]}$ or $0 \mu \mathrm{M}$ Fe(III)-EDTA [-Fe]. Data are means $\pm \mathrm{SE}$ of three replicates.

\begin{tabular}{|c|c|c|c|c|c|c|c|c|c|}
\hline \multirow{2}{*}{$\begin{array}{l}\text { Rootstock } \\
\text { Fe treatment }\end{array}$} & \multicolumn{2}{|c|}{ Adesoto } & \multicolumn{2}{|c|}{ Barrier } & \multicolumn{2}{|c|}{ GF 677} & \multicolumn{3}{|c|}{ Significance $^{\mathrm{a}}$} \\
\hline & {$[+\mathrm{Fe}]$} & {$[-\mathrm{Fe}]$} & {$[+\mathrm{Fe}]$} & {$[-\mathrm{Fe}]$} & {$[+\mathrm{Fe}]$} & {$[-\mathrm{Fe}]$} & $\mathrm{Fe}$ & $\mathrm{G}$ & $\mathrm{Fe} \times \mathrm{G}$ \\
\hline \multicolumn{10}{|l|}{ Organic acids } \\
\hline Citric acid & $1.06 \pm 0.33 b$ & $2.73 \pm 0.57 \mathrm{c}$ & $0.08 \pm 0.02^{\mathrm{b}} \mathrm{a}$ & $3.05 \pm 0.87 \mathrm{c}$ & $1.08 \pm 0.21 \mathrm{~b}$ & $1.65 \pm 0.45 \mathrm{bc}$ & $* * *$ & $* * *$ & $* * *$ \\
\hline Malic acid & $0.88 \pm 0.22$ & $2.09 \pm 0.44$ & $0.48 \pm 0.18$ & $2.00 \pm 0.69$ & $1.35 \pm 0.35$ & $1.71 \pm 0.40$ & $* *$ & NS & NS \\
\hline Succinic acid & $0.028 \pm 0.006 \mathrm{a}$ & $0.128 \pm 0.019 \mathrm{c}$ & $0.033 \pm 0.010 \mathrm{a}$ & $0.082 \pm 0.023 \mathrm{~b}$ & $0.045 \pm 0.008 \mathrm{a}$ & $0.062 \pm 0.014 \mathrm{ab}$ & $* * *$ & NS & $*$ \\
\hline Oxalic acid & $0.068 \pm 0.011$ & $0.096 \pm 0.009$ & $0.021 \pm 0.005^{\mathrm{b}}$ & $0.079 \pm 0.028$ & $0.059 \pm 0.017$ & $0.037 \pm 0.011^{\mathrm{b}}$ & NS & NS & NS \\
\hline Cis-aconitic acid $\left(\times 10^{-3}\right)$ & $2.46 \pm 0.76 \mathrm{ab}$ & $15.03 \pm 3.47 \mathrm{c}$ & $0.64 \pm 0.29 \mathrm{a}$ & $5.15 \pm 1.89 b$ & $3.58 \pm 0.47 b$ & $2.51 \pm 0.11 \mathrm{ab}$ & $* *$ & $* * *$ & $* *$ \\
\hline Quinic acid & $0.067 \pm 0.003$ & $0.077 \pm 0.014$ & $0.024 \pm 0.002$ & $0.082 \pm 0.030$ & $0.076 \pm 0.024$ & $0.154 \pm 0.054$ & $*$ & $*$ & NS \\
\hline
\end{tabular}

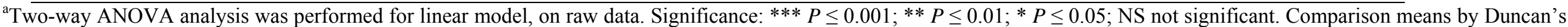

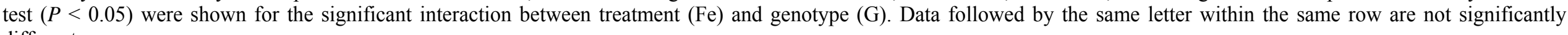
different.

${ }^{b}$ Below limit of quantification (LOQ). 


\section{Legend of figures}

Fig. 1. Root (A) and shoot (B) fresh weight and SPAD values of the third fully developed leaf from apex (C) for three Prunus rootstocks (Adesoto, Barrier and GF 677) after 14 days of growth in nutrient solution containing $90 \mu \mathrm{M}$ Fe(III)-EDTA [+Fe] or $0 \mu \mathrm{M}$ Fe(III)-EDTA [-Fe] . Vertical bars indicate SE of three replicates. Two-way ANOVA analysis to evaluate the Fe, genotype $(\mathrm{G})$ and interaction $(\mathrm{Fe} \times \mathrm{G})$ effects was performed. Significance: *** $P \leq 0.001 ; * * P \leq 0.01 ; * P \leq 0.05$; NS not significant. Comparison means by Duncan's test $(P<0.05)$ were shown for the significant interaction between treatment and genotype.

Fig. 2. Representative $1 \mathrm{D}{ }^{1} \mathrm{H} 500 \mathrm{MHz}-\mathrm{NMR}$ spectra of polar extracts of root tips from Adesoto genotype after 14 days of growth in nutrient solution containing $90 \mu \mathrm{M}$ Fe(III)-EDTA [+Fe]. The frames show a comparison between $[+\mathrm{Fe}]$ and $[-\mathrm{Fe}](0 \mu \mathrm{M}$ Fe(III)-EDTA $)$ treatments for some spectra portions.

Fig. 3. Sum of amino (A) and organic acids (B) (mg g $\left.{ }^{-1} \mathrm{FW}\right)$ determined by ${ }^{1} \mathrm{H} \mathrm{NMR}$, in root tip extracts of Prunus rootstocks (Adesoto, Barrier and GF 677) after 14 days of growth in nutrient solution containing $90 \mu \mathrm{M}$ Fe(III)-EDTA [+Fe] or $0 \mu \mathrm{M}$ Fe(III)-EDTA [-Fe] . Vertical bars indicate SE of three replicates. Two-way ANOVA analysis to evaluate the Fe, genotype $(\mathrm{G})$ and interaction $(\mathrm{Fe} \times \mathrm{G})$ effects was performed. Significance: $* * * P \leq 0.001 ; * * P \leq 0.01$; NS not significant.

Fig. 4. PCA analysis of 16 metabolites quantified using ${ }^{1} \mathrm{H}$ NMR and 6 organic acids quantified using mass spectrometry (MS) in root tip extracts of Adesoto (Ad), Barrier (Ba) and GF 677 (GF) plants grown during 14 days in nutrient solution containing $90 \mu \mathrm{M} F($ III)-EDTA [+Fe] or $0 \mu \mathrm{M}$ Fe(III)-EDTA [-Fe]. PC1/PC2 scores plot (A) explaining $57.8 \%$ of the total variance. Symbols:

$\mathrm{Ad}[+\mathrm{Fe}], \bullet \mathrm{Ba}[+\mathrm{Fe}], \mathbf{\mathrm { GF }}[+\mathrm{Fe}], \Delta \mathrm{Ad}[-\mathrm{Fe}], \circ \mathrm{Ba}[-\mathrm{Fe}], \square \mathrm{GF}[-\mathrm{Fe}] . \mathrm{PC} 1 / \mathrm{PC} 2$ loadings plot (B) generated from PCA analysis. Symbols: $\bigcirc$ sugars, $\bullet$ prunasin, $\bullet$ amino acids, $\square$ organic acids determined by NMR, $\boldsymbol{\square}$ organic acids determined by MS, $\Delta$ choline and $\boldsymbol{\Delta}$ unknown compound. Glu+Gln: sum of glutamic acid and glutamine. The dashed ellipses represent PC1 discrimination on the positive side ([-Fe] samples mainly separated due to alanine and organic acids). The solid ellipses represent PC2 discrimination on the positive side (Adesoto samples mainly separated due to choline and amino acids).

Fig. 5. Activity of phosphoenolpyruvate carboxylase (PEPC) (nmol $\mathrm{mg}^{-1} \mathrm{FW} \mathrm{min}{ }^{-1}$ ), in root tip extracts of Prunus rootstocks (Adesoto, Barrier and GF 677) after 14 days of growth in nutrient 
solution containing $90 \mu \mathrm{M}$ Fe(III)-EDTA [+Fe] or $0 \mu \mathrm{M}$ Fe(III)-EDTA [-Fe]. Data are means of three replicates. Vertical bars indicate SE of three replicates. Two-way ANOVA analysis to evaluate the $\mathrm{Fe}$, genotype $(\mathrm{G})$ and interaction $(\mathrm{Fe} \times \mathrm{G})$ effects was performed. Significance: *** $P \leq$ 0.001. Comparison means by Duncan's test $(P<0.05)$ were shown for the significant interaction between treatment and genotype. 
Fig 1.
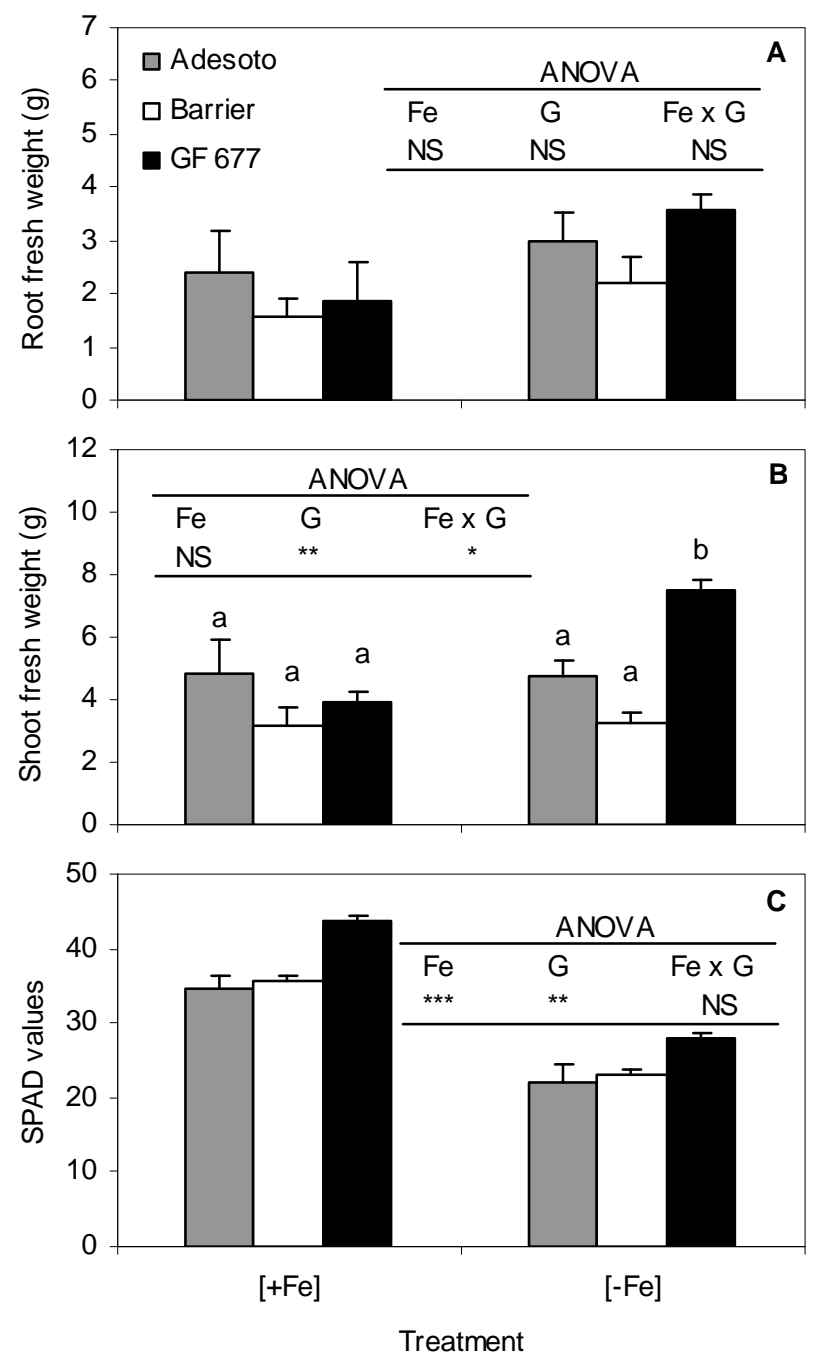
Fig. 2.

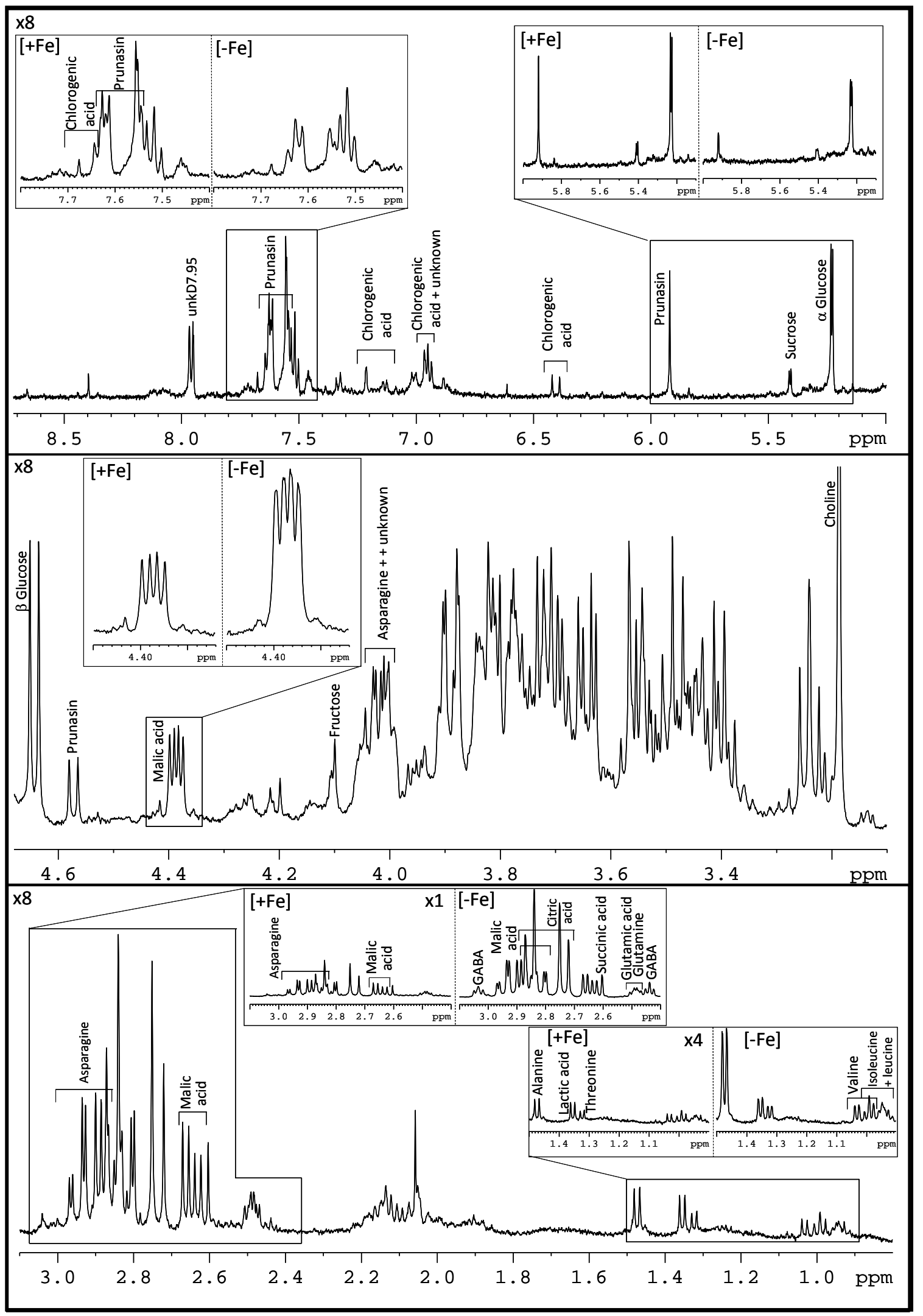


Fig. 3.
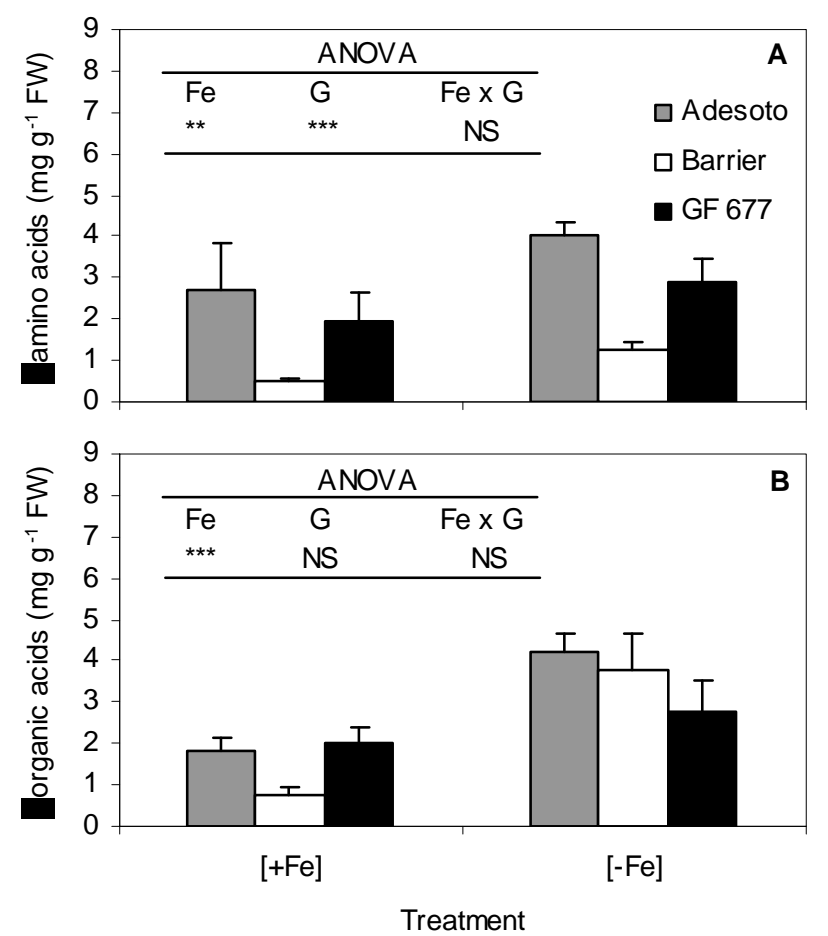
Fig. 4.
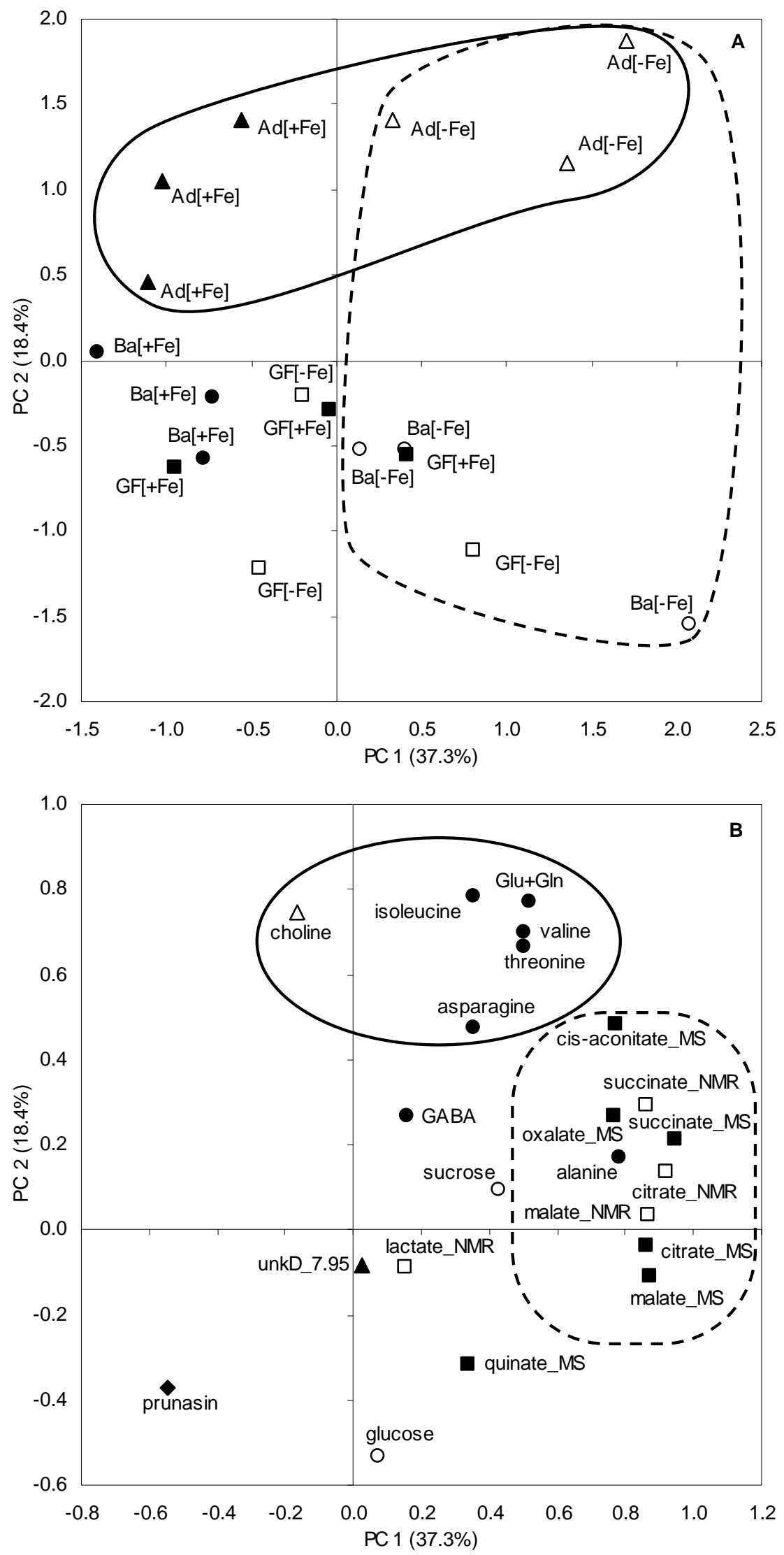
Fig. 5.

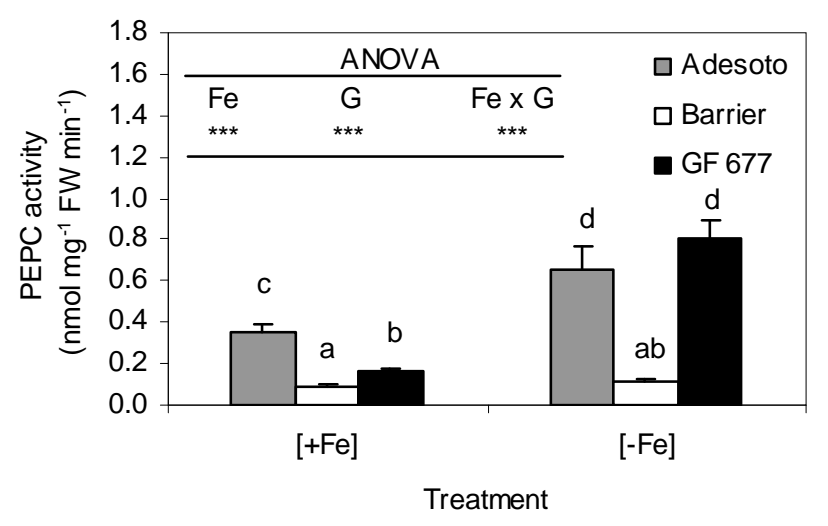

